\title{
The raw material basis of global value chains: allocating environmental responsibility based on value generation
}

\author{
Pablo Piñero ${ }^{\mathrm{a}^{*}}$, Martin Bruckner ${ }^{\mathrm{b}}$, Hanspeter Wieland ${ }^{\mathrm{b}}$, Eva Pongrácz ${ }^{\mathrm{a}}$, Stefan Giljum ${ }^{\mathrm{b}}$ \\ ${ }^{a}$ Energy and Environmental Engineering, Faculty of Technology, University of Oulu, Oulu, Finland \\ ${ }^{b}$ Institute for Ecological Economics, Vienna University of Economics and Business, Vienna, Austria \\ Contact: Pablo Piñero, Energy and Environmental Engineering, Faculty of Technology, P.O. Box 4300, \\ FI-90014 University of Oulu, Oulu, Finland. pablo.pinero@oulu.fi
}

\section{Acknowledgements}

We would like to thank three anonymous reviewers and the editor for their valuable comments and suggestions.

\section{Funding}

Pablo Piñero thanks the University of Oulu Graduate School and the Academy of Finland under the project Transition Pathways Towards Circular Economy - TRANSCIRC (App. No. 310405), for the financial support of this research. Martin Bruckner, Hanspeter Wieland and Stefan Giljum appreciate financial support by the ERC Grant 'FINEPRINT' (Grant No. 725525) from the European Commission.

\section{ORCID}

Pablo Piñero orcid.org/0000-0003-1027-944X

Martin Bruckner orcid.org/0000-0002-1405-7951

Hanspeter Wieland orcid.org/0000-0001-5944-7155

Eva Pongrácz orcid.org/0000-0002-2216-8328

Stefan Giljum orcid.org/0000-0002-4719-5867 


\title{
The raw material basis of global value chains: allocating environmental responsibility based on value generation
}

\author{
A new approach to allocate environmental responsibility, the "value added-based \\ responsibility' allocation, is presented in this article. This metric allocates total \\ environmental pressures occurring along an international supply chain to the \\ participating sectors and countries according to the share of value added they \\ generate within that specific supply chain. We show that - due to their position in \\ global value chains - certain sectors (e.g. services) and countries (e.g. Germany) \\ receive significantly greater responsibility compared to other allocation \\ approaches. This adds a new perspective to the discussions concerning a fair \\ distribution of mitigation costs among nations, companies and consumers.
}

Keywords: material flow accounting; material footprint; raw materials; shared responsibility; value added

\section{Introduction}

A typical supply chain starts with the extraction of raw materials, which are transformed into intermediate products using labour and capital, and subsequently processed to final goods or services. At each stage of processing, value is created in the form of payments for the factors of production (i.e. labour and capital). The supply chain-wide sum of these payments always adds up to the related expenditures of the final consumers. Similarly, at each step environmental pressure is generated in the form of emissions, waste or natural resource use. How much value added is captured by each one (e.g. Daudin et al., 2011; Foster-McGregor and Stehrer, 2013; Hummels et al., 2001; Koopman et al., 2010; Los et al., 2015) as well as how much responsibility in protecting the environment each actor should shoulder (e.g. Gallego and Lenzen, 2005; Lenzen et al., 2007; Marques et al., 2012; Peters, 2008; Rodrigues et al., 2006), have been object of extensive research. Building on these findings, a new approach for distributing 
environmental responsibility on a value added basis among actors participating in supply-chains, is presented in this paper. Although the focus is on raw materials as an example case, the method is in principle applicable to other environmental pressures as well.

Studies about the allocation of environmental responsibility focus on the quantification and distribution of environmental pressure and mitigation costs, according to the position and function of economic agents in global supply chains. Three main approaches have been introduced and discussed in the literature (see Steininger et al., 2015), which allocate environmental pressures and impacts completely to a particular group of agents and therefore addressed as 'full responsibility approaches' in this paper: production-based responsibility, consumption-based responsibility (Davis and Caldeira, 2010; Peters, 2008; Peters and Hertwich, 2008) and income-based responsibility (Marques et al., 2012). Differences between them lie in how environmental pressures and impacts of trade products are treated, and regarding the question, which agent bears the responsibility for mitigation (i.e. either the direct producer of pollution, the consumer of products from polluting production processes or the supplier of inputs to polluting production processes). However, these three full responsibility approaches, in which all the responsibility is allocated to only one group, reflect a very particular situation.

Alternative and potentially more realistic approaches are forms of 'shared responsibility', where all involved actors have to contribute a share to the total mitigation (Lenzen et al., 2007). Accordingly, there is another body of studies that concentrates on designing indicators of shared environmental responsibility (e.g. Csutora and Mózner, 2014; Gallego and Lenzen, 2005; Lenzen et al., 2007; Rodrigues et al., 2006; Temurshoev and Miller, 2015). An important reason to support shared 
responsibility approaches is that they could be perceived as fairer and thus receive higher support by those entities participating in a supply chain that would be stronger affected (i.e. a country, a firm or an individual) by one of the full allocation approaches. Shared responsibility thus might encourage efforts towards environment restoration or protection (Rodrigues et al., 2006).

In this paper, a new approach of allocating environmental responsibility called 'value added-based responsibility' is introduced. The rationale of this metric is the following: if the whole supply chain of a final product generates value at the expense of the environment, mitigation responsibilities should be equally shared among actors according to their share in the generated benefits, basically in the form of wages and profits. In a world with increasing labour division among sectors and countries, every company's activities and related profits are closely interlinked with, and dependent on, other businesses' activities. One could therefore argue that, for example, an insurance company should be attributed responsibility for the environmental pressures and impacts caused by its suppliers, but also by its customers.

The environmental pressure this study focuses on is raw material extraction. Two reasons explain this choice: first, the increasing dependence of modern economies on a wide range of materials (Greenfield and Graedel, 2013), some of them available only in a few locations but crucial for making highly profitable products. Second, the eminently 'glocal' character of some mining activities, primary serving global markets but mainly damaging local environments and landscapes (Suopajärvi et al., 2017).

In brief and paraphrasing Krugman (1995) and Timmer et al. (2015), if global value chains can be 'sliced up', then the metric introduced in this paper allocates environmental responsibility according to the slice's size. Similar attempts using value added for setting the responsibility shares among groups have been taken previously 
(Csutora and Mózner, 2014; Lenzen et al., 2007), although the allocation pathways differ, as it is explained in the next section. In addition, there are related studies focusing on measuring carbon embodiments of value added and derived trade balances on the basis of export decomposition methods (Meng et al., 2014; Xu et al., 2017). However, these studies do not explicitly focus on the distribution of responsibility in entire supply chains.

The rest of the paper is structured as following: In the next section, the three full allocation approaches (production-, consumption- and income- responsibilities) as well as recent shared approaches are further explained, and compared to the newly introduced value-added based responsibility. In section 3, a mathematical description of the methods is provided, while in section 4 the data sources and limitations are described. Section 5 presents and discusses the results for different allocations of raw material extraction both from a country and sector perspective. Section 6 concludes. A supporting information document (SI) complements this article.

\section{Approaches for allocating environmental responsibility}

The left side of Figure 1 provides a conceptual representation of the allocation pathways for the full and shared responsibility approaches, while the right one shows the calculation procedure and allocation pathway for the value added-based responsibility. The tree structure depicts flows of goods and money between the first three layers of a hypothetical supply chain serving final demand.

\subsection{Full responsibility approaches}


The production-based responsibility (also producer responsibility or territorial approach $)^{1}$ accounts for environmental pressures caused by economic processes within the country's territory (on a national scale), or within the firm's domain (on a micro level). That is, the producer responsibility considers the environmental pressures occurring within the limits of the orange sphere (i.e. territorial/producer allocation in Figure 1). Focusing on material extraction, the producer responsibility accounts for all raw materials from renewable and non-renewable sources extracted from the domestic environment, usually, biomass harvested by agriculture and forestry sectors and fossil fuels, metals and other non-metallic minerals removals by mining companies. In the producer approach, no allocation to traded products occurs.

[Figure 1. Near here]

Second, in the consumption-based responsibility (also upstream or consumer responsibility or consumer footprint), environmental pressures generated at different stages of the supply chain to produce final products are allocated to final demand. In the consumer footprint, allocation is thus performed following the green arrows in Figure 1 up to the final consumer. On a national level, the 'material footprint' records all raw material requirements for satisfying final demand, that is, it includes the domestically extracted resources and the raw materials embodied in imports, but excludes the raw material extracted related to exports. Consequently, the producer metric assigns greater

\footnotetext{
1 A further distinction would differentiate the extraction-based responsibility, from the production-based one (see Steininger et al., 2015), but this division is not needed for the purpose of this study.
} 
responsibility to extractive economies for commodity export, while the consumer approach allocates higher material use to high-income economies, with more pronounced levels of consumption (Bruckner et al., 2012). Another important issue is that, accounting for all material requirements of final demand shows that 'dematerialization' (or decoupling between growth in material use and growth in GDP), empirically observed for some economies (e.g. OECD, 2011), can vanish if domestic and foreign extractions required to satisfy domestic consumption are taken into account (Giljum et al., 2015a; Wiedmann et al., 2015). This occurs because of the international division of labour between suppliers and consumers of raw materials, and the outsourcing of material-intensive activities ${ }^{2}$. One disadvantage of the consumer responsibility is that it does not provide direct incentives to exporting countries to encourage changes in efficiency of their export industries. The consumption-based responsibility, however, could be 'technology-adjusted' to hold countries responsible for the technology in their exports, by comparing available production alternatives for the country's exports (e.g. world averages of environmental pressure intensity of exporting industries) with domestic technologies (Kander et al., 2015).

2 Similar situations have been observed for other environmental dimensions, notably the 'carbon leakage' as a consequence of off-sourcing carbon intensive companies to other locations (e.g. Davis and Caldeira, 2010; Peters, 2008; Peters et al., 2011; Peters and Hertwich, 2008). The consumer responsibility can be seen as an alternative approach to the territorial one in the application of measures to prevent the carbon leakage. Nonetheless, employing the consumer approach as a regulatory framework to assign responsibilities has been questioned, since due to general equilibrium effects (i.e. changes in global production and consumption patterns when reducing carbon emissions related to imports), there is not a direct link between a decrease in a country's footprint and a fall in global emissions (Jakob et al., 2014). 
Third, in the income-based responsibility approach (also downstream responsibility), environmental responsibility is allocated according to the income generated by payments to the owners of the factors of production. In this case, the allocation follows the pink arrows of Figure 1, i.e. from the downstream located polluting industry to the upstream participating sectors (the allocation is represented by a continuous border surrounding industries). The leading thought behind this allocation approach is that the suppliers of production inputs 'enable' environmental pressure by selling products that directly cause environmental pressure, or indirectly by being used as a necessary intermediate input for polluting industries, and are required to generate the country's income through wages, profits and rents (Lenzen and Murray, 2010; Marques et al., 2012). For the case of greenhouse gas emissions, this metric highlights the fact that fossil fuel exporters generate national income enabling a significant share of global emissions outside of their territories (Liang et al., 2017; Rodrigues et al., 2010). This metric has been applied to a much lesser extent and to our knowledge only to the case of carbon or greenhouse gas emissions (Ali, 2015; Liang et al., 2017; Liu et al., 2015; Marques et al., 2013, 2012; Rodrigues et al., 2010; Steininger et al., 2016; Su and Ang, 2015), or mercury emissions (Zhang et al., 2018). Regarding raw materials extraction, the allocation would follow the cascade of inter-industry transactions, from extractive industries to value added generation in upstream sectors supplying inputs (for example fuels and machinery used to extract raw materials) to mineral or biomass extracting sectors.

\subsection{Shared responsibility approaches}


These three full responsibility approaches are the starting point for the shared responsibility allocation methods ${ }^{3}$. In these approaches, the responsibility is shared between the producer, the upstream, and/or the downstream sectors and countries within the global supply chain. Gallego and Lenzen, (2005) propose a method for sharing responsibility based on a parameter that fractions the responsibility into two shares. The first remains as producer responsibility (represented by the orange circle in Fig 1) and another share is allocated either to suppliers (shared producer and income responsibility), or consumers (shared producer and consumer responsibility). This approach is further elaborated by Lenzen et al. (2007), Lenzen (2007) and Lenzen (2008), who propose value added shares to net output and final use to gross output, as sharing parameters in, respectively, upstream and downstream shared responsibility. An advantage of using value added in comparison to a fix/constant percentage as sharing parameter (e.g. $50 \%$ responsibility is retained and the other half is passed on to subsequent actors) is a lower aggregation variance, i.e. the results are less affected by the number of steps in the supply chain (Lenzen, 2007).

In parallel, Rodrigues et al. (2006) select a group of desirable properties for a shared responsibility indicator, and conclude that the average of the income and consumer responsibilities could be regarded as such an indicator. A detail comparison between these two proposals is provided in Rodrigues and Domingos (2008) and replied in Lenzen (2008). Empirical applications of the approach set out in Lenzen et al. (2007) and Lenzen (2007) can be found in Andrew and Forgie (2008) and for both approaches in Zhou and Marques (2013).

Further, two alternative shared producer and consumer responsibility approaches have been developed. Csutora and Mózner (2014) propose a 'beneficiary-based' shared

3 Names of shared approaches are based on Zhou and Marques, (2013), and they don't always coincide in the literature. 
responsibility approach between producers and consumers, in which the apportioning criteria follows the distinction between benefits of production (i.e. gross value added to gross output) and those of consumption (i.e. value of material throughput). Value added is selected for determining the producer share, because it reflects production-related gains accrued by an actor belonging to a supply chain. This was also the original motivation for allocating environmental responsibility to value added in the metric introduced in this paper. However, another reason for using value added is that it can be considered a proxy for effective control on production of participating agents in a supply chain (Lenzen et al., 2007). According to this interpretation, low value added producers receive lower responsibility because they are constrained by their operating inputs and as a result, have modest influence over its suppliers or customers. A similar reasoning is followed by Temurshoev and Miller (2015) but instead of value added, they propose a 'distance-based' shared responsibility, which employs average distances between primary inputs suppliers, producers and consumers, as an indicator for an actor's control over a supply chain and thus, to levy responsibility. In both cases, the influence (and the responsibility) diminishes further away in the supply chain from the producer of the pollution (Lenzen et al., 2007; Temurshoev and Miller, 2015).

\subsection{Value added-based responsibility approaches}

In the value added-based responsibility, total supply-chain wide environmental pressures are allocated upstream to participating actors according to their shares in the supply-chain wide value generation. Like the producer and consumer shared responsibilities proposed by Csutora and Mózner (2014) and Lenzen et al. (2007), and the income responsibility and related shared approaches, the value added-based responsibility allocates environmental pressure according to value added. However, 
instead of an allocation from the sector where pressure occurs to the value added of downstream industries or upstream suppliers, environmental responsibility is first allocated downstream to final demand, and then reallocated from there to all value generating sectors within the global supply chain of a specific final demand product or sector. This is illustrated in the right side of Figure 1: the producer responsibility (step one) is allocated to consumers (step two), which is then re-allocated to profiteers (step three). The final allocation is described by the blue arrows and assigns higher responsibility to those actors profiting to a larger extent from being embedded in the supply chain (e.g. brand holders of high tech products). From a methodological point of view, the consumer responsibility is only an intermediate step.

Our newly introduced approach features characteristics of both full and shared responsibility approaches. It could be considered a 'full responsibility' approach, because it allocates responsibility to only one group of actors, i.e. producers of value added. Therefore, in the value added-based responsibility, no environmental responsibility is shouldered by final consumers, which differentiates the approach from the shared income (or producer) and consumer responsibility. However, in shared responsibility approaches, the notion of 'producer responsibility' is sometimes extended to include downstream enabled pressures and impacts (see Rodrigues and Domingos, 2008) or upstream embodied ones ${ }^{4}$ (shared producer and consumer). The latter addresses producers as intermediate consumers (Zhou and Marques, 2013) and would thus result in an 'intermediate consumer responsibility' approach. On this basis, the value added-based responsibility introduced in this paper could also be considered a shared producer and intermediate consumer approach. This would be as well the case if shared approaches are defined by the allocation direction, i.e. upstream and downstream from where the pollution occurs (layer 1 in Figure 1). In summary, whether this

${ }_{4}$ This definition would be related to the notion of 'producer's footprint'. 
approach shall be labelled as a full or a shared responsibility method depends on the definition of the two categories. Under a narrow definition of full approaches, in which production-based responsibility refers exclusively to producers of polluting products and consumption-based to final consumers, the value added-based responsibility could be considered as a form of full downstream responsibility. In contrast, under a broader definition of producers and consumers, which expands the category, respectively, to producers of necessary inputs of pollution processes and intermediate consumers, the value added-based responsibility could be categorized as a shared responsibility.

\section{Methods}

In the implementation of both full and shared responsibility approaches, input-output models have been widely employed. These models, originally introduced by Leontief (1936), are based on input-output tables, which describe interdependencies in the economy recording transactions among sectors, flows of primary inputs and final uses. Using matrix notation, $Z$ displays intermediate deliveries between industries, that is, element $z_{i j}$ refers to product flows from sector $i$ to sector $j, y$ is final uses of products, whose $y_{i}$ describes final use of products from sector $i$, and $p$ is payments to sellers of primary inputs (or value added in production), where $p_{j}$ accounts for primary inputs required by sector $j$. The core principle in input output tables is that total output must be equal to total input per sector, and gross output $x$ equals all sales for intermediate production plus final uses, that is, $x=Z i+y$, whereas gross input $x^{\prime}$ equals all interindustry purchases plus payments for primary inputs, $x^{\prime}=i^{\prime} Z+p$ (for further details see Miller and Blair, 2009). Henceforth, capital and minor letters respectively denote matrix and column-vector, while prime indicates transposition. $i$ is a column-vector of ones and $I$ is the identity matrix. $\hat{x}$ is the diagonal matrix of vector $x$, and $\hat{x}^{-1}$ denotes matrix 
inversion of $\hat{x}$.

On the basis of input-output tables, the demand- and supply-driven input-output models can be estimated. The demand-driven or Leontief model is denoted by

$$
x=(I-A)^{-1} y=B y
$$

where $A=Z \hat{x}^{-1}$ is the direct input coefficients matrix, whose element $a_{i j}=z_{i j} / x_{j}$ expresses direct input requirements from sector $i$ per unit of output of sector $j$; and $B=(I-A)^{-1}$ is the 'Leontief inverse', whose element $b_{i j}$ indicates total input requirements of sector $i$ per unit of final use of products from sector $j$.

On the other hand, the supply-driven or Ghosh model (Ghosh, 1958) is given by

$$
x=\left(I-\dot{A}^{\prime}\right)^{-1} p=G^{\prime} p
$$

where $A=\hat{x}^{-1} Z$ is the direct sales matrix, whose element $\dot{a}_{i j}=z_{i j} / x_{i}$ is the output share of sector $i$ utilized by sector $j$; and $G=\left(I-A^{\prime}\right)^{-1}$ is the 'Ghosh inverse' (also called output inverse or total sales matrix), whose element $g_{i j}$ displays total output of sector $i$ utilized by sector $j$ per unit of primary inputs from sector $i$. The term supply-driven (in contrast to demand-driven) has been questioned for giving the misleading impression that two distinct models exists (Nakamura and Kondo, 2009). Its interpretation has been also object of discussion (e.g. Dietzenbacher, 1997; Guerra and Sancho, 2011;

Oosterhaven, 2012, 1988). In this study an ex-post (i.e. purely descriptive) interpretation as suggested in Gallego and Lenzen (2005), is followed.

The production-based environmental account, expressed as an absolute measurement in physical units $e^{\prime}$ (in this study tons of raw materials extracted), sets the starting point for the consumption- and income-based responsibility allocation, in which territorial values are attributed to final consumers and sellers of primary inputs, 
respectively. The consumption-based responsibility is based on the demand-driven model,

$$
t^{\prime}=f^{\prime} B \hat{y}
$$

in which $f^{\prime}=e^{\prime} \hat{x}^{-1}$ is a vector of environmental pressure intensity (e.g. raw material extraction per unit of output) and $t$ is the total upstream environmental pressure for a final uses bundle $y$.

In the income-based responsibility approach, the supply-driven model is further extended,

$$
n^{\prime}=f^{\prime} G^{\prime} \hat{p},
$$

where product $f^{\prime} G^{\prime}$ quantifies the downstream cumulative environmental pressure per unit of primary inputs utilized or absorbed, and $n$ accounts for the total downstream environmental pressure induced by the total payments to a supplier of primary inputs.

\subsection{Introducing value added-based responsibility}

For the newly introduced value added-based responsibility allocation, the starting point is the monetary value added $g$ created along a supply chain by a given final demand $y$, which can be calculated using

$$
g=\hat{v} B y
$$

where $\hat{v}$ is the direct value added shares matrix obtained following $\hat{v}=\hat{p} \hat{x}^{-1}$, and the product $\hat{v} B$ describes shares of induced value added per unit of final demand. All terms are in monetary units in equation (5), where $g$ is obtained aggregating the value added induced by a final use $y$ at each production stage. An analogous principle is 
applied in the value added-based responsibility $h$ to re-allocate supply chain-wide environmental pressures (i.e. upstream responsibility) $t$. That is, instead of final use $y$, upstream environmental responsibility of a final use $t$ from equation 3 is distributed following value added captures,

$$
h=\hat{v} B t .
$$

Revisiting Figure 1, in step two the producer responsibility $e$ (obtained in step 1) is allocated to consumers $y$ following equation (3). In step three, the consumer responsibility $t$ is then re-allocated to upstream sectors according to product $\hat{v} B$ following equation (6) resulting inh. The consumer responsibility $t$ is employed to allocate environmental pressures from primary production to final demand, but with the single aim to then re-allocate it again to all entities participating in the supply chain according to their value added shares. In this way, the value added-based responsibility holds accountable all profiteers (value generators) along the entire supply chains. Consequently, the value-added responsibility differs from the income responsibility in that the latter assigns responsibility to the upstream suppliers only $\left(f^{\prime} G^{\prime}\right)$.

Moreover, since the value added-based approach simply re-allocates the consumption-based responsibility, it is worth to describe in more detail the differences between both approaches, which reflects in the different approach towards the origin (domestic vs. abroad) of value added absorbed by domestic and foreign final uses. This is clearer appreciated if equation (6) is slightly modified and further developed for two agents (e.g. countries) $r$ and $s$,

$$
H=\hat{v} B \hat{t}=\left(\begin{array}{ll}
v_{r} b_{r r} t_{r} & v_{r} b_{r s} t_{s} \\
v_{s} b_{s r} t_{r} & v_{s} b_{s s} t_{s}
\end{array}\right),
$$


where each element $h_{i j}=v_{i} b_{i j} t_{j}$ holds either an index $i$ indicating origin of value added, an index $j$ denoting origin of final products, or both.

From the perspective of the consumer responsibility, two components for each agent can be distinguished in $H$. For instance, the upstream environmental burden of final products from $r$ can be decomposed according to the value added domestically generated and absorbed $v_{r} b_{r r} t_{r}$, and the foreign value added domestically absorbed $v_{s} b_{s r} t_{r}$. In the value added-based responsibility approach, however, the second component is substituted by the part of upstream environmental pressure of final products from $s$, which is re-allocated following the value added domestically generated but absorbed abroad $v_{r} b_{r s} t_{s}$. In other words, the consumer responsibility of region $r$ can be calculated by summing over column $r$ of matrix $H$, while the value added-based responsibility of region $r$ can be determined by summing over row $r$ of matrix $H$. An equivalent statement applies for $s$. Therefore, the higher the share of domestic value added in foreign final use, the greater the amount of environmental pressures reallocated under the value added-based logic, as well as the gap between both metrics ${ }^{5}$. Furthermore, $H$ does not distinguish the origin of raw materials. However, defining matrix $T=\hat{f} B \hat{y}$ and obtaining $H^{i}$,

$$
H^{i}=\hat{v} B T^{\prime} \text {, }
$$

\footnotetext{
For example, on the basis of equation (7), differences between value added- and consumption-based responsibility can be developed following:

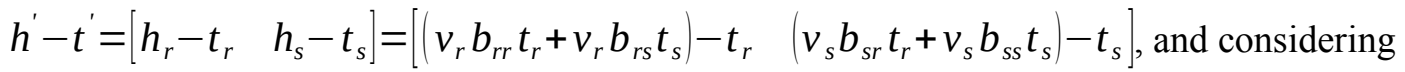
that $i^{\prime} \hat{v} B=i$ that is, $v_{r} b_{r r}+v_{s} b_{s r}=1$ and $v_{r} b_{r s}+v_{s} b_{s s}=1$, they can be explained in function of domestic vs. foreign absorptions: $i$.
} 
it is possible to split the allocations according to the origin of the extractions. Summing by column $i^{\prime} H^{i}=i^{\prime} \hat{v} B T^{\prime}=i^{\prime} \hat{y} B^{\prime} \hat{f}=x \hat{f}=e$, and by row $H^{i} i=\hat{v} B T^{\prime} i=\hat{v} B t=h$, that is, producer and value added-based responsibilities are respectively obtained. Diagonal elements in $H^{i}$ are domestic extractions, whereas off-diagonal ones refer to extractions from foreign environments.

Finally, to understand the differences between the full approaches and the one proposed in this paper, the 'production layer decomposition' (PLD) technique, which enables a precise assessment of environmental pressure for each production round or layer (Lenzen and Crawford, 2009), can be employed. For applying PLD to the consumer responsibility, the product $f^{\prime} B \hat{y}$ can be decomposed using a power series expansion $f^{\prime} B \hat{y}=f^{\prime} \hat{y}+f^{\prime} A \hat{y}+f^{\prime} A^{2} \hat{y} \ldots i t^{0^{\prime}}+t^{1^{\prime}}+t^{2^{\prime}} \ldots i t^{\prime}$. Likewise, PLD can be applied to the income responsibility employing $f^{\prime} G^{\prime} \hat{p}=f^{\prime} \hat{p}+f^{\prime} A^{\prime} \hat{p}+f^{\prime} A^{2} \hat{p} \ldots \dot{i} n^{0 \prime}+n^{1{ }^{\prime}}+n^{2{ }^{\prime}} \ldots \dot{i} n$ . Lastly, in the value added-based responsibility, environmental pressure from each round can be re-allocated along the supply chain decomposing the product $\hat{v} B t$, that is, $\hat{v} B t=\hat{v} B t^{0}+\hat{v} B t^{1}+\hat{v} B t^{2} \ldots i h^{0^{\prime}}+h^{1^{\prime}}+h^{2^{\prime}} \ldots \dot{i} h^{\prime 6}$.

${ }^{6} \quad$ The generic expression of the PLD applied to the consumer responsibility for the $k$ layer under analysis is $t^{k^{\prime}}=f^{\prime} A^{k} \hat{y}$. Since there are an infinite number of layers, a residual term $B^{i}$ can be calculated for the threshold $q$, following $B^{i}=B-I-\sum_{\mathrm{k}=1}^{\mathrm{q}} \mathrm{A}^{\mathrm{k}}$ (Giljum et al., 2016). The equivalent expression to equation 3 for the residual is $t^{b^{\prime}}=f^{\prime} B^{i} \hat{y}$. Similarly, a generic expression for the income approach is $n^{n^{\prime}}=f^{\prime} \dot{A}^{k^{\prime}} \hat{p}$ and a residual term can be estimated following $G^{i}=G-I-\sum_{\mathrm{k}=1}^{\mathrm{q}} \dot{A}^{\mathrm{k}}$, so the allocation for the residual is $n^{i^{\prime}}=f^{\prime} G^{i^{\prime}} \hat{y}$. The generic expression to the value added-based responsibility is $h^{k}=\hat{v} B t^{k}$. 


\section{Data sources and limitations}

The focus of our analysis is on the material foundations of global value chains and for this reason, a global multi-region input-output (MRIO) model has been employed. Different MRIO databases exist, with dissimilar coverage and classifications (Tukker and Dietzenbacher, 2013) and moreover, diverging results have been reported in footprint-type assessments, also for raw material flows (Eisenmenger et al., 2016; Giljum et al., 2017, 2015b). Currently, efforts are being undertaken to explore differences among them (e.g. Arto et al., 2014; Inomata and Owen, 2014; Moran and Wood, 2014; Owen et al., 2016; Wieland et al., 2017). In general, it is acknowledged that the choice should depend on the goals of the research. The Eora MRIO database ${ }^{7}$ (Lenzen et al., 2013, 2012), has been selected for three reasons: its high country resolution (189 countries), the availability of time series (from 1990 to 2013), and the acceptable level of disaggregation of raw material extracting sectors, basically agriculture, forestry and mining. Apart from the differences among databases, all MRIO models suffer from uncertainties introduced during data compilation and balancing, and assumptions regarding, for instance, homogeneity in prices or sectoral and country aggregation (Lenzen, 2000; Wiedmann, 2009). Six categories of primary inputs are considered in Eora: compensation of employees, taxes on production, subsidies on production, net operating surplus, net mixed income, and consumption of fixed capital; which compose the gross value added (i.e. gross output minus intermediate consumption). In general, net value added (i.e. gross value added minus consumption of fixed capital), is considered a superior approach for measuring value added creation, since consumption of fixed capital is actually a production cost (OECD et al., 2009). Nevertheless, due to the difficulties in the measurement of consumption of fixed capital,

Version v.199.82 (available at http://www.worldmrio.com/). 
gross value added is commonly used in policy reports and studies, which is also the choice in this study. Further, tables in basic prices are assumed to be more stable (Lenzen et al., 2004) and have been used for estimating the consumption-based responsibility. For the income- and value added-based responsibility, the primary inputs table at basic prices and the intermediate transactions at purchasers' prices have been utilized. The reason for using purchasers' prices for the intermediates is that if basic prices are employed, product $\hat{v} B$ causes an imperfect allocation, i.e. the system is not balanced, since net taxes and subsidies on products for intermediate consumption are excluded. Finally, for presenting results by sector and regional groups, an ad-hoc aggregation key to ten common sectors and ten world regions has been developed (see SI).

Physical data for raw material extraction have been gathered from the UNEP International Resource Panel database (Schandl et al., 2016), one of the most detailed and comprehensive global raw material extraction databanks available. It covers 44 aggregated raw material categories for all countries worldwide, compiled following standardized principles of 'economy-wide material flow accounting' (e.g. Eurostat, 2013; OECD, 2008). However, data quality among raw material categories varies notably and despite being the largest flow, estimates of sand, gravel and other construction minerals are usually considered to be the poorest (Miatto et al., 2016).

Finally, population and GDP data have been collected from the World Bank(The World Bank Group, 2017), with the exception of Eritrea and Taiwan, obtained from the United Nations World Population Prospects (United Nations, 2017).

\section{Results and discussion}

This section is structured in three parts: In subsection 5.1 we estimate and compare 
allocation of raw material extractions for all approaches (production-, consumption-, income-, and value added-based responsibility). In subsection 5.2 we explore the reasons for the differences between consumer and value added-based responsibility. Finally, in subsection 5.3 we assess dematerialization trends comparing the consumer responsibility approach with the value added-based approach for the period 1990-2013.

\subsection{A comparison of all responsibility approaches for raw material extraction}

Figure 2 maps the highest material responsibility in mass units per capita by type for all countries in Eora. Results support and expand previous findings regarding the geographic distribution of raw material extraction and use: to satisfy their needs and fuel their economies, high income countries often rely on raw materials extracted outside their territories. Many of the OECD economies therefore exhibit the highest responsibility under the consumer perspective (e.g. USA, Mexico, UK, South and Eastern Europe, New Zealand). However, a number of countries and regions (e.g. Central and Northern Europe, Canada, Japan, South Korea) receive even higher footprints from the value added-based perspective. That is, the material basis of the value added that these countries are able to appropriate along the global supply chains in which they operate, exceeds the amounts of raw material required to sustain their final demands. In contrast, in non-OECD economies across South America, Africa, Middle East, and Central Asia and Pacific, producer and income responsibilities predominate, while consumer and value ones are rarely the highest (only for Philippines and Thailand for value added-based responsibility). This is a typical profile of low and middleincome countries, which are specialising in material-intensive extraction activities and exports, while their generation of value added is limited compared to actors across the supply chains that use these raw materials. The map does not inform about the gap 
among accounting methods, but in SI (sheet 'Countries') can be seen that, in general, the income-based responsibility is relatively closer to the territorial approach than the other two metrics, which could explain the similar geographical distribution observed in Figure 2.

[Figure 2. Near here]

Figure 3 displays production, income-, consumption- and value added-based responsibilities per capita and domestic versus foreign origin of materials in the year 2013. Countries are ordered by their absolute number for value added-based responsibility, shown with a dot in the figure. The first row shows the ten largest per capita raw material responsibilities based on the value added-based approach, whereas the second one displays selected examples (results for all countries are available in the SI).

Germany and France hold the same stair-shape profile, although the steps are remarkably more distant for Germany, whose value added-based responsibility is $40 \%$ higher than its consumer footprint. This means that the economic position of Germany in international supply chains allows the country to appropriate a comparably high share of the value added. It is interesting to see that the income responsibility draws on around $50 \%$ of domestic raw material extraction within Germany, while both consumer and value added-based responsibility reveal a high dependence on foreign raw materials. France shows similar dependencies. Furthermore, notable differences between consumer and value added-based responsibilities are observed for Belgium and The Netherlands, and beyond the EU, for Australia and Switzerland. These differences arise from foreign raw materials, which in the cases of Belgium and Switzerland play an 
overwhelming role. As a result, for these two countries, the raw material basis of value added creation is around $85 \%$ higher than the materials needed for satisfying their final demands. For non-OECD economies, the most significant gap appears for Russia, an extractive economy serving international markets, which has managed to capture higher shares of value added, interestingly, on the basis of foreign raw materials (although on a smaller scale, a similar pattern is also observed for Venezuela). On the contrary, for those countries with higher consumer responsibility, the difference to the value addedbased approach is in general less prominent (e.g. China, USA, India, UK, Turkey, Vietnam or Ukraine), with the exception of Singapore (a highly open small economy, whose score must be taken with caution).

Table 1 complements Figure 3 presenting aggregated results by world regions for all four approaches. It can be stated that in general, OECD economies depend on non-OECD resources for maintaining their consumption and generation of value added. On a finer scale, Latin America, Middle East, Africa, rest of Asia and Pacific (this category excludes China, Taiwan, South Korea and Japan), are primary raw material providers, while the NAFTA bloc and above all the EU, are at the other side of the spectrum. These results highlight not only the reliance of EU's and NAFTA's consumption of foreign natural resources, already acknowledged in many studies (e.g. Bruckner et al., 2012; Muñoz et al., 2009; Schoer et al., 2012; Tukker et al., 2014; Wiebe et al., 2012; Wiedmann et al., 2015), but the high physical dependency on raw materials from foreign origin for the generation of value added in these economies.

[Figure 3. Near here]

[Table 1. Near here] 
Figure 4 shows the global values for production-, income-, consumption- and value added-based responsibility by aggregated sector in the year 2013 (disaggregated results by sector and country in SI). By applying PLD, raw material allocation is split into three layers. Almost all extractions originate in the mining, agriculture and forestry sectors, and to some extent in the food industry. The first key message is that producer and income responsibility present comparable scores, because in the income approach more than half of the raw material is allocated to the primary inputs of the extractive sectors, that is, at layer $0\left(f^{\prime} \hat{p}\right)$. Taking up again the example of Australia, this implies that in the income responsibility the extracted raw materials are allocated to the production inputs of the Australian mining sector, which to a great share are produced domestically. The second key message is that differences between consumer and value added-based responsibility are remarkable for services, construction and food industry, arising in further away tiers of the supply chain (second layer or further). Regarding to services, it has been pointed out that indirect dependencies in global value chains hide the vulnerability of value added creation and employment in the service sectors due to international competition (Daudin et al., 2011). Figure 4 complements this idea suggesting that services, an immaterial sector by definition, can be as well appreciably affected by, for instance, raw material supply shortage or resource efficiency measures. Thus, even though the idea is less intuitive and requires a broader framing than for example for high-tech industries, value added created in service sectors (essential in high income economies), are embedded in an intricate network of physical and monetary flows. On the other hand, the outcome for the food industry suggests that this sector is important for providing final products, as can be expected for nourishment needs, but less relevant as a source of value added itself. The high consumer responsibility for the construction sector can be explained by the fact that in 
conventional input-output models, uses of dwellings and civil engineering are accounted as fixed capital formation. Although there have been already some attempts to internalize (i.e. endogenize) these final uses into the transactions matrix (i.e. IO table) (e.g. Schoer et al., (2012)), this model variation requires extra data and assumptions, and so far is less common in the literature. Interestingly, Figure 4 also shows that in the value added-based approach, a significant amount of raw materials is re-assigned back to the extractive sectors. Lastly, a negative allocation is observed for the consumer responsibility at the first layer of the mining sector. This is caused by negative final uses of category 'changes in inventories', for Turkey's other mining and quarrying and the US' coal mining and oil and gas extraction (see SI). In a similar way, negatives can arise on income- and value added-based responsibilities for a given sector or a country when primary inputs are negative (there are multiple examples in the SI), which raises new questions regarding to the interpretation of these outcomes. Considering that for the particular case of raw materials producer and income metrics bring similar results, in the following we concentrate on further explaining differences between consumer and value added-based responsibility.

[Figure 4. Near here]

\subsection{Differences between consumer and value added-based responsibilities}

The patterns of differences between consumer and value added-based responsibilities are studied in more detail based on Figure 5, which depicts exported domestic value added absorbed by foreign final uses vs. foreign value added absorbed by domestic final uses (left), as well as upstream raw materials re-allocated to exported value added vs. upstream raw materials re-allocated to imported value added (right), for the twenty-five highest value added trading countries in year 2013. The interpretation of the graph is as 
follows: economies above the 45 grades line (left) export more domestic value added than they import from abroad, whereas the situation is the opposite for countries below the line. A completely closed economy would be in the origin. The material reallocation (right) is determined by the supply chain-wide material intensity ( $\mathrm{kg} / \mathrm{dollar}$ ) of the value traded. Countries above the line hold higher value added-based responsibility, while those below receive higher consumer responsibility. It can be observed that in general, there are little differences regarding to countries' positions from a monetary perspective versus the perspective of embodied raw materials, that is, net exporters of value added also hold a higher value added-based responsibility and the other way around. For instance, value added embodied in the exports of countries such as Germany, Italy and France is mirrored by a higher value added-based responsibility compared to their consumer responsibility. At the same time, for countries like the UK or the USA value added of imports exceeds that embodied in exports, and correspondingly the consumer responsibility is larger than the value added-based responsibility.

There are, however, some exceptions. Globally, upstream raw materials per dollar of value added exported or imported are around $1.4 \mathrm{~kg} /$ dollar, although for some countries there are notable differences depending on the trade flow. China is a net exporter of domestic value added, but the raw material turnover of its imported value added is around $3.2 \mathrm{~kg} /$ dollar, whereas for the exports it is just $1.7 \mathrm{~kg} /$ dollar, displacing the country's position below the 45 degree line in the right graph. This indicates that the foreign value added absorbed by Chinese final demand is generated in more material intensive supply chains than the domestic one absorbed outside China. A similar situation is observed for Mexico. For other countries, such as Australia, Japan or South Korea, the situation is the opposite. For example, the upstream material intensity of 
Australia for imported foreign value added is $0.9 \mathrm{~kg} /$ dollar, while exports of domestic value added require more than twice as much materials per dollar. Similar patterns are observed for other countries with high domestic extraction (e.g. Saudi Arabia, Argentina, Chile, Brazil, etc. full list in SI).

[Figure 5. Near here]

\subsection{Dematerialization trends from a value added perspective}

Figure 6 offers relative changes in GDP, consumer and value added-based responsibilities for selected countries and regions between years 1990 and 2013 (results for all countries between 1990 and 2013 available in the SI). This figure aims to complement the discussion about dematerialization trends for countries and world regions provided in Wiedmann et al., (2015), regarding to absolute, relative or nonexistent decoupling between economic growth and material use. It can be seen that for the non-OECD economies (first row) and the OECD as a region, the same trend is maintained in both cases, that is, when a materialization is observed following the consumer perspective, it also arises in the value approach. For Russia ${ }^{8}$, and to some extent Brazil and Indonesia, value added-based responsibility has grown faster, whereas the opposite can be said for $\mathrm{China}^{9}$ and India. More surprising results are seen in the second row. For Germany, the absolute decoupling observed under the consumer responsibility approach, vanishes since the beginning of the century when looking at value added-based responsibility. Although less accentuated, a comparable trend is

8 An outlier for Russia for 1998 has been removed by linear interpolation.

9 Note the different scale in Figure 6 for China compared to other countries in the first row. 
observed for France. This implies that some countries have consolidated their large stake in value added in increasingly material intensive global value chains, while keeping the growth of the consumption footprint at moderate (or even negative) rates. This is usually achieved by a trade surplus. On the contrary, the USA reveals a more pronounced decoupling for the value added-based responsibility, whereas for Japan and Canada both responsibilities run at similar paces.

All in all, it can be stated that allocation of environmental loads according to value gains can provide a new viewpoint to the discussions about resource efficiency strategies (i.e. towards the dematerialization of economies) and the distribution of mitigation costs, since depending on the country or industry under scrutiny, both territorial responsibility and consumer footprint can differ notably from the value added-based responsibility. This also raises new questions regarding how policies aiming for optimizing a country's positioning in global value chains should be formulated and aligned with sustainability principles, especially if trends of global fragmentation accentuate in the next decades.

[Figure 6. Near here]

\section{Conclusions and future research}

Different approaches for allocating environmental pressures and impacts across countries and sectors have been introduced. Most widely known are the production (or territorial), the consumption (or upstream), and the income (or downstream) perspective. Valid arguments support all these allocation approaches: the direct producers of pollution, the consumers that induce it through their demand, or the owners of the factors of production that enable it; all actors could be held accountable for damaging the environment. However, the fact that under each allocation scheme there 
are beneficiaries and more adversely affected parties, favoring any of these allocations could inhibit the implementation of environmental protection measures, as the agent most injured may always claim unequal or unfair treatment. Therefore, attempts to share environmental responsibility among participating actors of a supply chain have been introduced, combining accounting principles from producer, consumer and/or income responsibility.

In this paper a new responsibility accounting method, the 'value added-based responsibility', has been introduced, which investigates how the creation of economic gains (value added) relates to the supply chain-wide (upstream and downstream) environmental pressures and impacts, i.e. the responsibility of an agent being part of a global value chain that requires natural resources or causes environmental damage. The method re-allocates the total supply chain-wide upstream environmental pressure (i.e. the consumer footprint) to the various sectors and countries that form part of each global supply chain according to their respective share in the supply chain-wide value created. The basic logic behind this method is that in order to create a certain value added, sectors (and countries) require involvement in supply chains with specific upand downstream structures. Applying this approach, a sector or country that is able to benefit economically from a certain position in a global supply chain can be made responsible for a certain share of the environmental pressure that all actors along this supply chain together generate.

We demonstrated that for some countries and sectors, applying value added shares as an allocation principle can significantly increase or decrease total environmental responsibility in comparison to the consumer or income responsibility approaches. Increases can be observed for countries such as Germany or for the service 
sector in general, while decreases are found e.g. for the USA or the aggregated food industry. This is an important contribution to ongoing discussions, for example, in ecological economics and political ecology regarding the distribution of economic gains versus environmental burdens in the current globalised economic system. It points to the question, which actors should engage in designing and implementing (policy) measures to achieve a balanced way of development, i.e. which does not further accelerate current economic or environmental inequalities between countries and world regions.

In this context, many issues need to be further explored. One example is the question, to what extent applying this logic could originate contradictions or counter-productive effects. What if one actor in a supply chain ends up bearing higher mitigation costs simply because it manages to be more efficient, that is, if ceteris paribus it generates more value added than another one with the same inputs array? Or what new distortions and interpretation challenges could appear as a result of allocating physical quantities to monetary flows, especially for the case of negatives (e.g. subsidies)?

In addition, a finer look to different primary input categories or material groups could provide valuable insights to comprehend more thoroughly the global governance of raw materials and current economic inter-dependencies in global value chains. Addressing this question would also bring closer studies on vertical specialization and material flows, offering not only possible solutions to environmental concerns, but to other more uncertain harms, such as the supply risks of strategic resources. Further, even though this study adopts a macro perspective concentrating on countries and industries, similar accounting principles can be applied on a corporate or product level. This would contribute to bridge the research on business administration, ethics and corporate social responsibility to the one on environmental footprints and life-cycle assessment of products. Finally, the approach can also be applied to other environmental 
loads, such as greenhouse gas emissions, water, land use, etc., thus increasing the understanding of the complex web of interactions between the social and natural spheres.

\section{Disclosure statement}

No potential conflict of interest was reported by the authors.

\section{References}

Ali, Y. (2015) Measuring CO2 emission linkages with the hypothetical extraction method (HEM). Ecological Indicators, 54, 171-183.

Andrew, R. and V. Forgie (2008) A three-perspective view of greenhouse gas emission responsibilities in New Zealand. Ecological Economics, 8, 194-204.

Arto, I., J.M. Rueda-Cantuche and G.P. Peters (2014) Comparing the GTAP-MRIO and WIOD Databases for Carbon Footprint Analysis. Economic Systems Research, $26,327-353$.

Bruckner, M., S. Giljum, C. Lutz and K.S. Wiebe (2012) Materials embodied in international trade - Global material extraction and consumption between 1995 and 2005. Global Environmental Change, 22, 568-576.

Csutora, M. and Z.V. Mózner, (2014) Proposing a beneficiary-based shared responsibility approach for calculating national carbon accounts during the postKyoto era. Climate Policy 14, 599-616.

Daudin, G., C. Rifflart and D. Schweisguth (2011) Who produces for whom in the world economy? Canadian Journal of Economics/Revue Canadienne D’Economique, 44, 1403-1437.

Davis, S.J. and K. Caldeira (2010) Consumption-based accounting of CO2 emissions. Proceedings of the National Academy of Sciences, 107, 5687-5692.

Dietzenbacher, E. (1997) In Vindication of the Ghosh Model: A Reinterpretation as a Price Model. Journal of Regional Science, 37, 629-651. 
Eisenmenger, N., D. Wiedenhofer, A. Schaffartzik, S. Giljum, M. Bruckner, H. Schandl, T.O. Wiedmann, M. Lenzen, A. Tukker and A. de Koning (2016) Consumption-based material flow indicators - Comparing six ways of calculating the Austrian raw material consumption providing six results. Ecological Economics, 128, 177-186.

Eurostat (2013) Economy-wide Material Flow Accounts (EW-MFA) Compilation Guide 2013.

Foster-McGregor, N. and R. Stehrer (2013) Value added content of trade: A comprehensive approach. Economics Letters, 120, 354-357.

Gallego, B. and M. Lenzen (2005) A consistent input-output formulation of shared producer and consumer responsibility. Economic Systems Research, 17, 365391.

Ghosh, A. (1958) Input-Output Approach in an Allocation System. Economica, 25, 5864.

Giljum, S., M. Bruckner and A. Martinez (2015a) Material footprint assessment in a global input-output framework. Journal of Industrial Ecology, 19, 792-804.

Giljum, S., S. Lutter, M. Bruckner, H. Wieland, N. Eisenmenger, D. Wiedenhofer and H. Schandl (2017) Empirical assessment of the OECD Inter-Country InputOutput database to calculate demand-based material flows (ENV/EPOC/WPEI(2017)1, OECD, Paris).

Giljum, S., S. Lutter, H. Wieland, N. Eisenmenger, D. Wiedenhofer, A. Schaffartzik, H. Schandl and J. West (2015b) An empirical assessment comparing input-outputbased and hybrid methodologies to measure demand-based material flows (ENV/EPOC/WPEI(2015)1, OECD, Paris).

Giljum, S., H. Wieland, S. Lutter, M. Bruckner, R. Wood, A. Tukker and K. Stadler (2016) Identifying priority areas for European resource policies: a MRIO-based material footprint assessment. Journal of Economic Structures, 5, 1-24.

Greenfield, A. and T.E. Graedel (2013) The omnivorous diet of modern technology. Resources, Conservation and Recycling, 74, 1-7.

Guerra, A.-I. and F. Sancho (2011) Revisiting the original Ghosh Model: Can it be made more plausible? Economic Systems Research, 23, 319-328.

Hummels, D., J. Ishii and K.-M. Yi (2001) The nature and growth of vertical specialization in world trade. Journal of International Economics, 54, 75-96. 
Inomata, S. and A. Owen (2014) Comparative evaluation of MRIO Databases. Economic Systems Research, 26, 239-244.

Jakob, M., J.C.Steckel and O. Edenhofer (2014) Consumption- Versus ProductionBased Emission Policies. Annual Review of Resource Economics, 6, 297-318. Kander, A., M. Jiborn, D.D. Moran and T.O. Wiedmann (2015) National greenhousegas accounting for effective climate policy on international trade. Nature Climate Change, 5, 431-435.

Koopman, R., W. Powers, Z. Wang and S.-J. Wei (2010). Give credit where credit is due: tracing value added in global production chains (NBER Working Paper No. 16426, Cambridge MA).

Krugman, P. (1995) Growing World Trade: Causes and Consequences. Brookings Papers on Economic Activity, 26, 327-377.

Lenzen, M. (2008) Consumer and producer environmental responsibility: A reply. Ecological Economics, 66, 547-550.

Lenzen, M. (2007) Aggregation (in-) variance of shared responsibility: A case study of Australia, Ecological Economics, 64, 19-24.

Lenzen, M. (2000) Errors in Conventional and Input-Output—-based Life-Cycle Inventories. Journal of Industrial Ecology, 4, 127-148.

Lenzen, M. and R. Crawford (2009) The path exchange method for hybrid LCA. Environmental Science and Technology, 43, 8251-8256.

Lenzen, M., K. Kanemoto, D. Moran and A. Geschke (2012) Mapping the structure of the world economy. Environmental Science and Technology, 46, 8374-8381.

Lenzen, M., D. Moran, K. Kanemoto and A. Geschke (2013) Building Eora: a Global Multi-Region Input-Output Database At High Country and Sector Resolution. Economic Systems Research, 25, 20-49.

Lenzen, M. and J. Murray (2010) Conceptualising environmental responsibility. Ecological Economics, 70, 261-270.

Lenzen, M., J. Murray, F. Sack and T. Wiedmann (2007) Shared producer and consumer responsibility - Theory and practice. Ecological Economics, 61, 2742.

Lenzen, M., L.-L. Pade and J. Munksgaard (2004) CO2 Multipliers in Multi-region Input-Output Models. Economic Systems Research, 16, 391-412.

Leontief, W. (1936) Quantitative Input and Output Relations in the Economic Systems of the United States. The Review of Economics and Statistics, 18, 105-125. 
Liang, S., S. Qu, Z. Zhu, D. Guan and M. Xu (2017). Income-Based Greenhouse Gas Emissions of Nations. Environmental Science and Technology, 51, 346-355.

Liu, H., W. Liu, X. Fan and Z. Liu (2015) Carbon emissions embodied in value added chains in China. Journal of Cleaner Production, 103, 362-370.

Los, B., M.P. Timmer and G.J. de Vries (2015) How global are global value chains? A new approach to measure international fragmentation. Journal of Regional Science, 55, 66-92.

Marques, A., J. Rodrigues and T. Domingos (2013) International trade and the geographical separation between income and enabled carbon emissions. Ecological Economics, 89, 162-169.

Marques, A., J. Rodrigues, M. Lenzen and T. Domingos (2012) Income-based environmental responsibility. Ecological Economics, 84, 57-65.

Meng, B., G. Peter and Zhi Wang (2014) Tracing CO2 Emissions in Global Value Chains (Office of Economics Working Paper No. 2014-12A, Washington).

Miatto, A., H. Schandl, T. Fishman and H. Tanikawa (2016) Global Patterns and Trends for Non-Metallic Minerals used for Construction. Journal of Industrial Ecology, $21,1-14$.

Miller, R.E. and P.D. Blair (2009) Input-Output Analysis: Foundations and extensions. Second Edition. Cambridge, Cambridge University Press.

Moran, D. and R. Wood (2014) Convergence Between the Eora, WIOD, EXIOBASE, and OpenEU's Consumption-Based Carbon Accounts. Economic Systems Research, 26, 245-261.

Muñoz, P., S. Giljum and J. Roca (2009) The Raw Material Equivalents of International Trade. Empirical Evidence for Latin America. Journal of Industrial Ecology, 13, 881-897.

Nakamura, S. and Y. Kondo (2009) Waste Input-Output Analysis. Concepts and Application to Industrial Ecology. Dordrecht, Springer.

Oosterhaven, J. (1988) On the plausibility of the supply-driven Input-Output Model. Journal of Regional Science, 28, 203-217.

Oosterhaven, J. (2012) Adding Supply-Driven Consumption makes the Ghosh Model even more implausible. Economic Systems Research, 24, 101-111.

Organisation for Economic Co-operation and Development (OECD) (2008) Measuring material flow and resource productivity. Volume I. The OECD guide (OECD, Paris). 
Organisation for Economic Co-operation and Development (OECD) (2011) Towards Green Growth: Monitoring Progress. OECD Indicators (OECD, Paris).

Organisation for Economic Co-operation and Development (OECD), United Nations (UN), International Monetary Fund (IMF), World Bank (WB), and European Commission (EC) (2009) System of National Accounts 2008.

Owen, A., R. Wood, J. Barrett and A. Evans (2016) Explaining value chain differences in MRIO databases through structural path decomposition. Economic Systems Research, 28, 243-272.

Peters, G.P. (2008) From production-based to consumption-based national emission inventories. Ecological Economics, 65, 13-23.

Peters, G.P. and E.G. Hertwich (2008) Post-Kyoto greenhouse gas inventories: production versus consumption. Climatic Change, 86, 51-66.

Peters, G.P., J.C. Minx, C.L. Weber and O. Edenhofer (2011) Growth in emission transfers via international trade from 1990 to 2008. Proceedings of the National Academy of Sciences, 108, 8903-8908.

Rodrigues, J. and T. Domingos (2008) Consumer and producer environmental responsibility: Comparing two approaches. Ecological Economics, 66, 533-546.

Rodrigues, J., T. Domingos, S. Giljum and F. Schneider (2006) Designing an indicator of environmental responsibility. Ecological Economics, 59, 256-266.

Rodrigues, J., A. Marques and T. Domingos (2010) Carbon Responsibility and Embodied Emissions. Theory and measurement. New York, Routledge.

Schandl, H., M. Fischer-Kowalski, J. West, S. Giljum, M. Dittrich, N. Eisenmenger, A. Geschke, et al. (2016) Global Material Flows and Resource Productivity. Assessment Report for the UNEP International Resource Panel (United Nations Environment Programme).

Schoer, K., J. Weinzettel, J. Kovanda, J. Giegrich and C. Lauwigi (2012) Raw material consumption of the European Union - Concept, Calculation Method, and Results. Environmental Science and Technology, 46, 8903-9.

Steininger, K.W., C. Lininger, L.H. Meyer, P. Muñoz and T. Schinko (2016) Multiple carbon accounting to support just and effective climate policies. Nature Climate Change, 6, 35-41.

Su, B. and B.W. Ang (2015) Multiplicative decomposition of aggregate carbon intensity change using input-output analysis. Applied Energy, 154, 13-20. 
Suopajärvi, L., T. Ejdemo, E. Klyuchnikova, E. Korchak, V. Nygaard and G.A. Poelzer (2017) Social impacts of the "glocal" mining business: case studies from Northern Europe. Mineral Economics, 30, 31-39.

Temurshoev, U. and R.E. Miller (2015) Distance-based shared responsibility (paper presented at the 22th International Conference on Input-Output Techniques. Lisbon, Portugal).

The World Bank Group (2017) The World Bank DataBank, http://databank.worldbank.org/data/home.aspx.

Timmer, M.P., A.A. Erumban, B. Los, R. Stehrer, G.J. de Vries (2014). Slicing Up Global Value Chains. Journal of Economic Perspectives, 28, 99-118.

Tukker, A., T. Bulavskaya, S. Giljum and A. de Koning (2014) The Global Resource Footprint of Nations. Carbon, water, land and materials embodied in trade and final consumption calculated with EXIOBASE 2.1 (Leiden/Delft/Vienna/Trondheim).

Tukker, A. and E. Dietzenbacher (2013) Global Multiregional Input-Output Frameworks: an Introduction and Outlook Global Multiregional Input-Output. Economic Systems Research, 25, 1-19.

United Nations, Department of Economic and Social Affairs, Population Division (2017). World Population Prospects: The 2017 Revision, https://esa.un.org/unpd/wpp/.

Wiebe, K.S., M. Bruckner, S. Giljum, C. Lutz and C. Polzin (2012) Carbon and materials embodied in the international trade of emerging economies: A multiregional input-output assessment of trends between 1995 and 2005. Journal of Industrial Ecology, 16, 636-646.

Wiedmann, T. (2009) A review of recent multi-region input-output models used for consumption-based emission and resource accounting. Ecological Economics, $69,211-222$.

Wiedmann, T.O., H. Schandl, M. Lenzen, D. Moran, S. Suh, J. West and K. Kanemoto. (2015) The material footprint of nations. Proceedings of the National Academy of Sciences of the United States of America, 112, 6271-6276.

Wieland, H., S. Giljum, M. Bruckner, A. Owen and R. Wood (2018) Structural production layer decomposition: a new method to measure differences between MRIO databases for footprint assessments. Economic Systems Research, 30, 6184. 
Xu, X., M. Mu and Q. Wang (2017) Recalculating CO2 emissions from the perspective of value-added trade: An input-output analysis of China's trade data. Energy Policy, 107, 158-166.

Zhang, H., L. Chen, Y. Tong, W. Zhang, W. Yang, M. Liu, L. Liu, H. Wang and X. Wang (2018) Impacts of supply and consumption structure on the mercury emission in China: An input-output analysis based assessment. Journal of Cleaner Production, 170, 96-107.

Zhou, X. and A. Marques (2013) Accounting for Environmental Responsibility: A Case of Asian Countries Using the Asian International Input-Output Model. In: J. Murray and M. Lenzen (eds.), The Sustainability Practitioner's Guide to MultiRegional Input-Output Analysis. Champaign, USA, Common Ground, 148-164. 
Figure 1. Approaches for environmental responsibility allocation (left) and calculation procedure for the value added-based responsibility (right).

Figure 2. World distribution of highest responsibility (raw material extraction in mass units/per capita) by country in year 2013.

Figure 3. Production-, income-, consumption- and value added-based responsibility per capita and total value added-based responsibility for selected countries and origin of materials in year 2013.

Figure 4. World production-, income-, consumption- and value added-based responsibility by sector in year 2013 .

Figure 5. Exported domestic value added (DVA) absorbed by foreign final uses vs. foreign value added (FVA) absorbed by domestic final uses (left), and upstream raw materials (RM) re-allocated to exported DVA vs. upstream raw materials (RM) reallocated to imported FVA (right), for the twenty-five higher value added trading countries in year 2013.

Figure 6. Relative changes in GDP, consumption- and value added-based responsibility for selected countries and regions between years 1990 and 2013. 
Table 1. Production-, income-, consumption- and value added-based responsibility by world regions in Million tons (Mt) and tons per capita (t/cap).

\begin{tabular}{ccccccccc}
\hline & $\begin{array}{c}\text { Producer } \\
(\mathbf{M t})\end{array}$ & $\begin{array}{c}\text { Income } \\
(\mathbf{M t})\end{array}$ & $\begin{array}{c}\text { Consumer } \\
(\mathbf{M t})\end{array}$ & $\begin{array}{c}\text { Value } \\
(\mathbf{M t})\end{array}$ & $\begin{array}{c}\text { Producer } \\
\text { (t/cap) }\end{array}$ & $\begin{array}{c}\text { Income (t// } \\
\text { cap) }\end{array}$ & $\begin{array}{c}\text { Consumer } \\
\text { (t/cap) }\end{array}$ & $\begin{array}{c}\text { Value } \\
\text { (t/cap) }\end{array}$ \\
\hline OECD & 18,594 & 19,846 & 28,331 & 29,733 & 14.7 & 15.7 & 22.4 & 23.5 \\
Non-OECD & 62,563 & 60,214 & 52,826 & 50,190 & 10.6 & 10.2 & 8.9 & 8.5 \\
\hline European Union & 5,148 & 4,691 & 10,593 & 11,762 & 10.3 & 9.4 & 21.3 & 23.6 \\
NAFTA & 8,562 & 9,307 & 10,898 & 10,448 & 18.1 & 19.6 & 23.0 & 22.0 \\
East Asia & 29,869 & 26,749 & 31,216 & 29,502 & 19.2 & 17.2 & 20.0 & 18.9 \\
Rest of Europe & 1.403 & 2,167 & 1,273 & 1,563 & 14.4 & 22.2 & 13.1 & 16.0 \\
S. America \& Caribe & 6,092 & 6,982 & 5,062 & 4,988 & 12.4 & 14.2 & 10.3 & 10.2 \\
Middle East & 4,507 & 4,664 & 2,889 & 2,843 & 14.1 & 14.5 & 9.0 & 8.9 \\
Rest of Asia \& Pac. & 20,668 & 20,774 & 16,439 & 15,990 & 7.7 & 7.7 & 6.1 & 5.9 \\
Africa & 4,907 & 4,725 & 2,786 & 2,827 & 4.7 & 4.5 & 2.7 & 2.7 \\
\hline
\end{tabular}

Totals are not equal due to 'Statistical Discrepancies' category in Eora. Producer $=$ Producer responsibility, Income $=$ Income responsibility, Consumer $=$ Consumer responsibility, Value $=$ Value added-based responsibility 


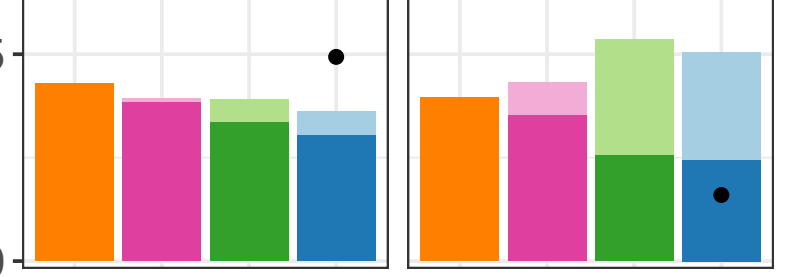

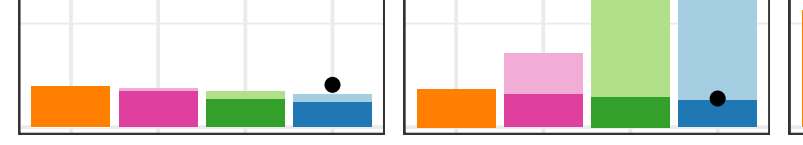

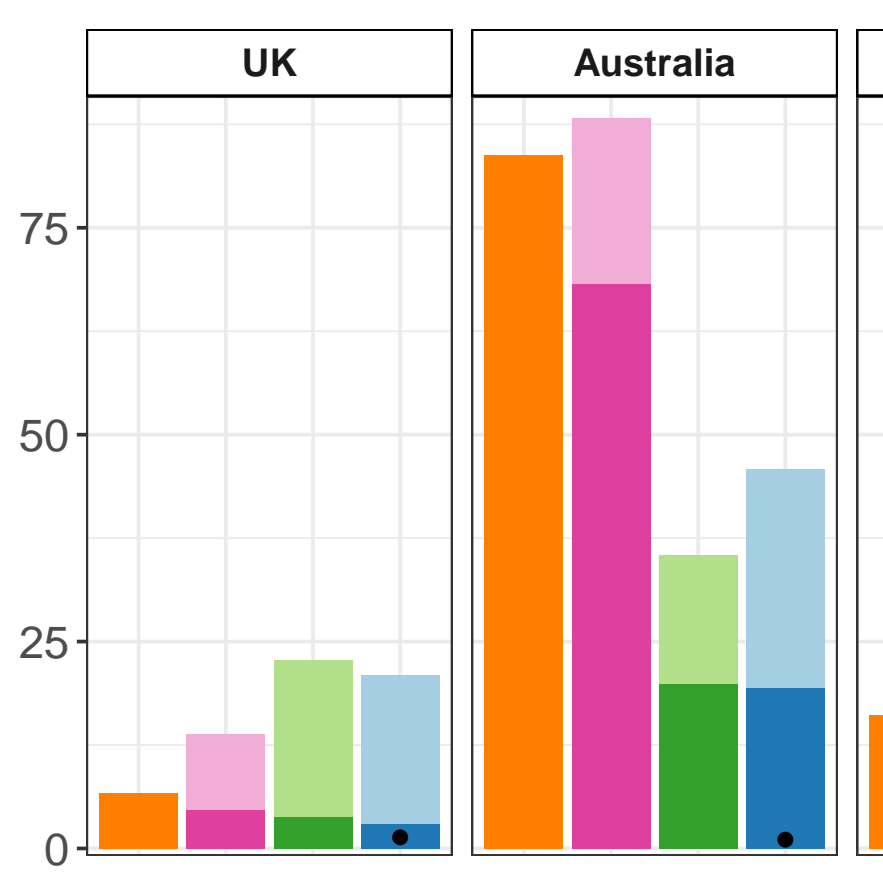

\begin{tabular}{|c|}
\hline Turkey \\
\hline
\end{tabular}

\section{Belgium

Switzerland

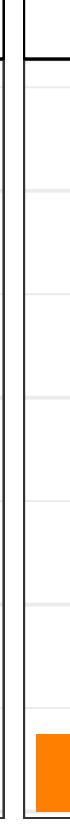

\section{t/cap}

Producer

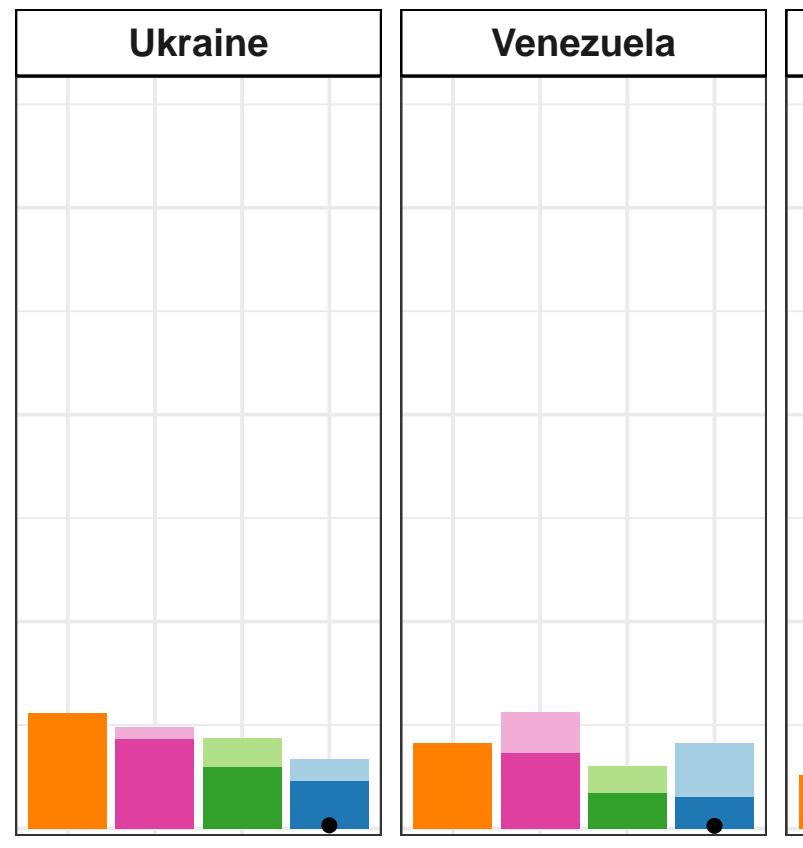

Singapore 


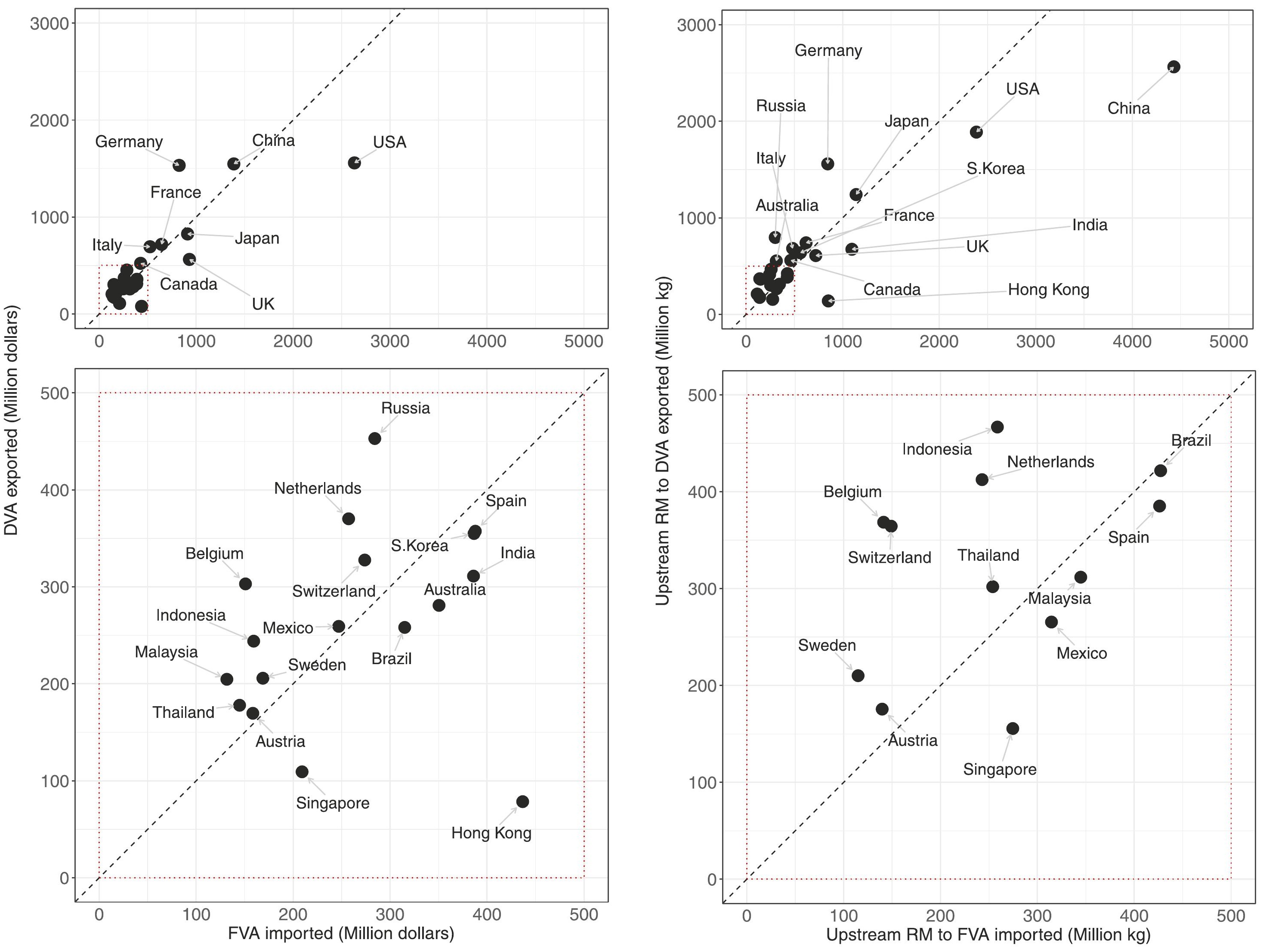




\section{China}

India

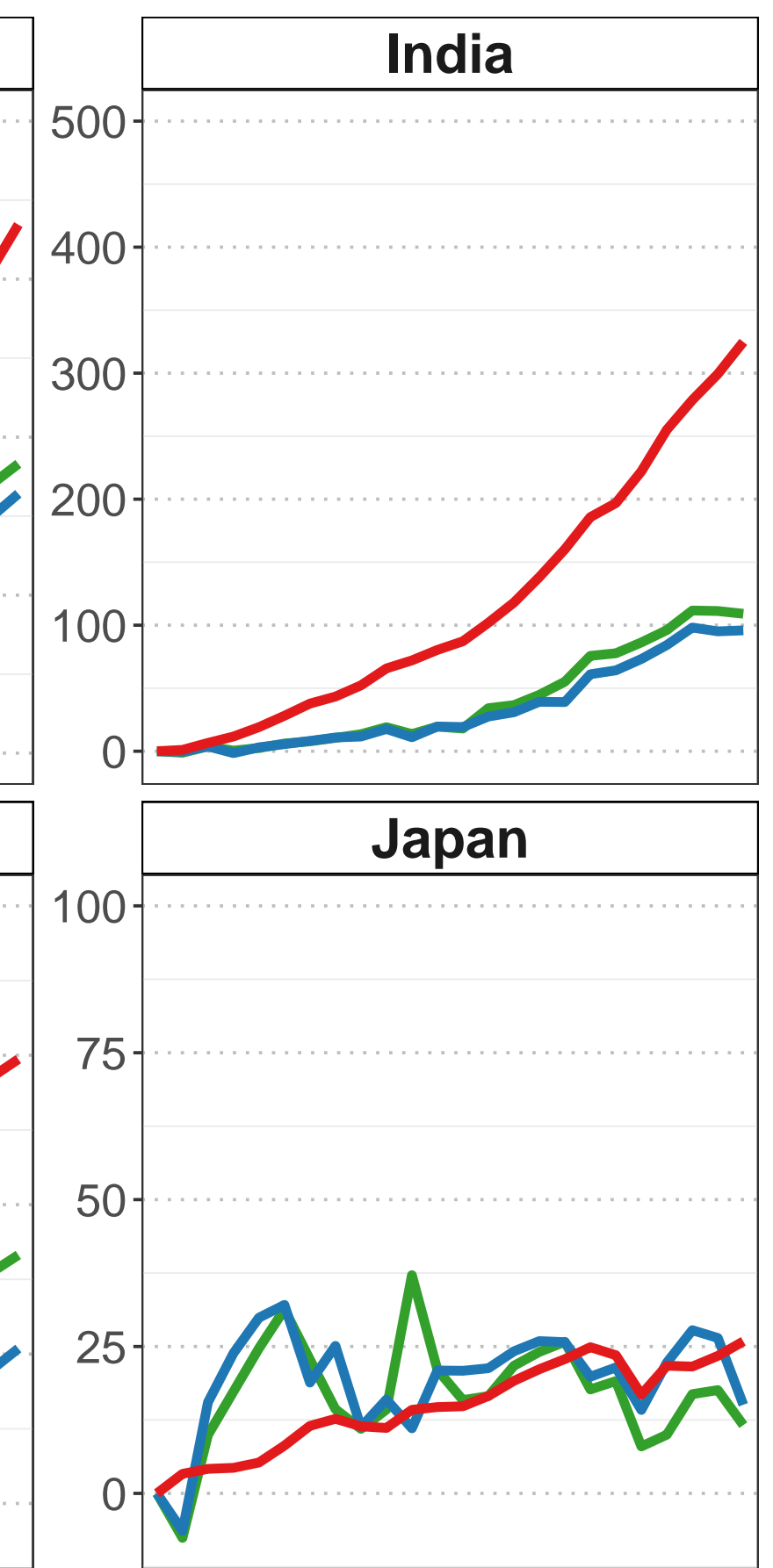

19901995200020052010

19901995200020052010

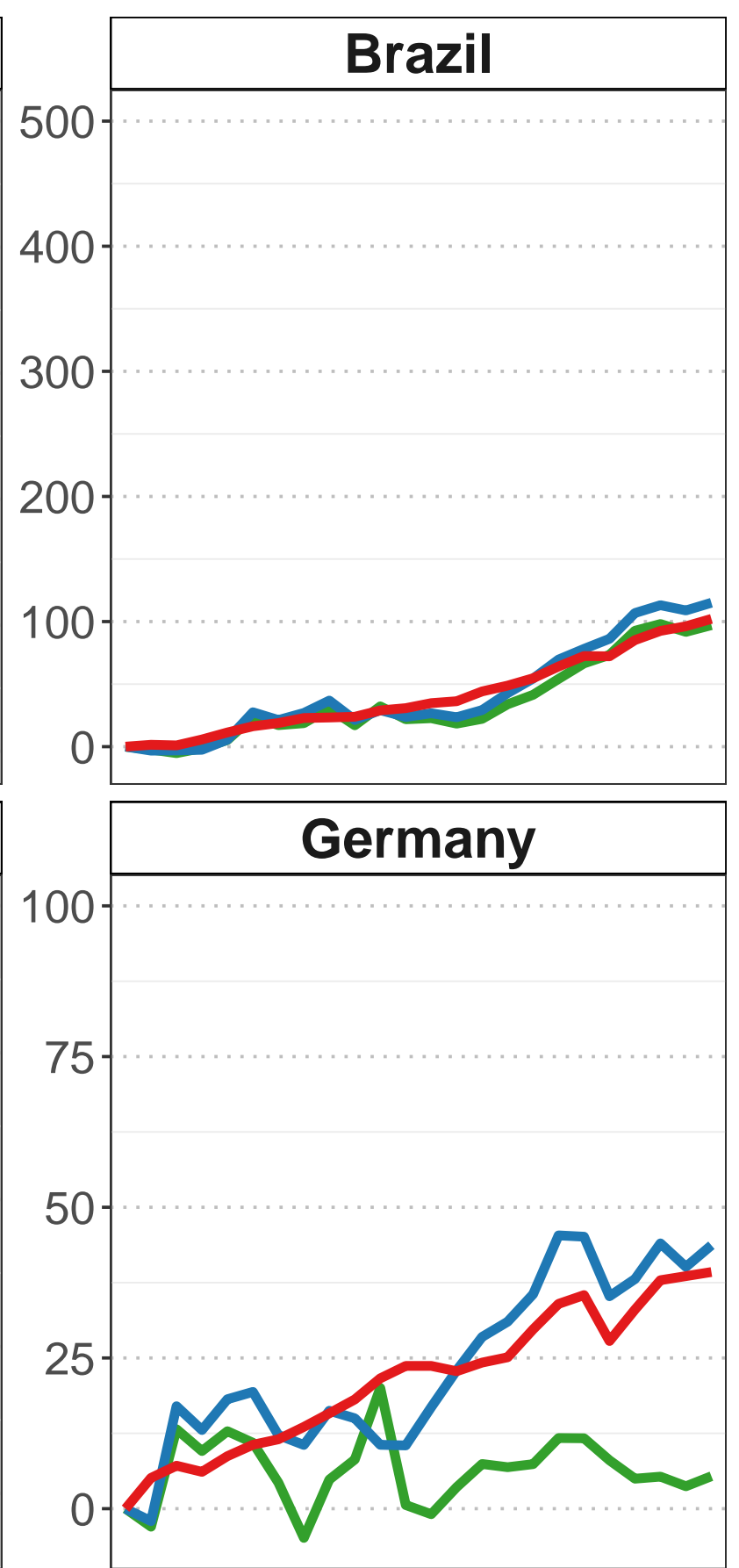

19901995200020052010

\section{Brazil}

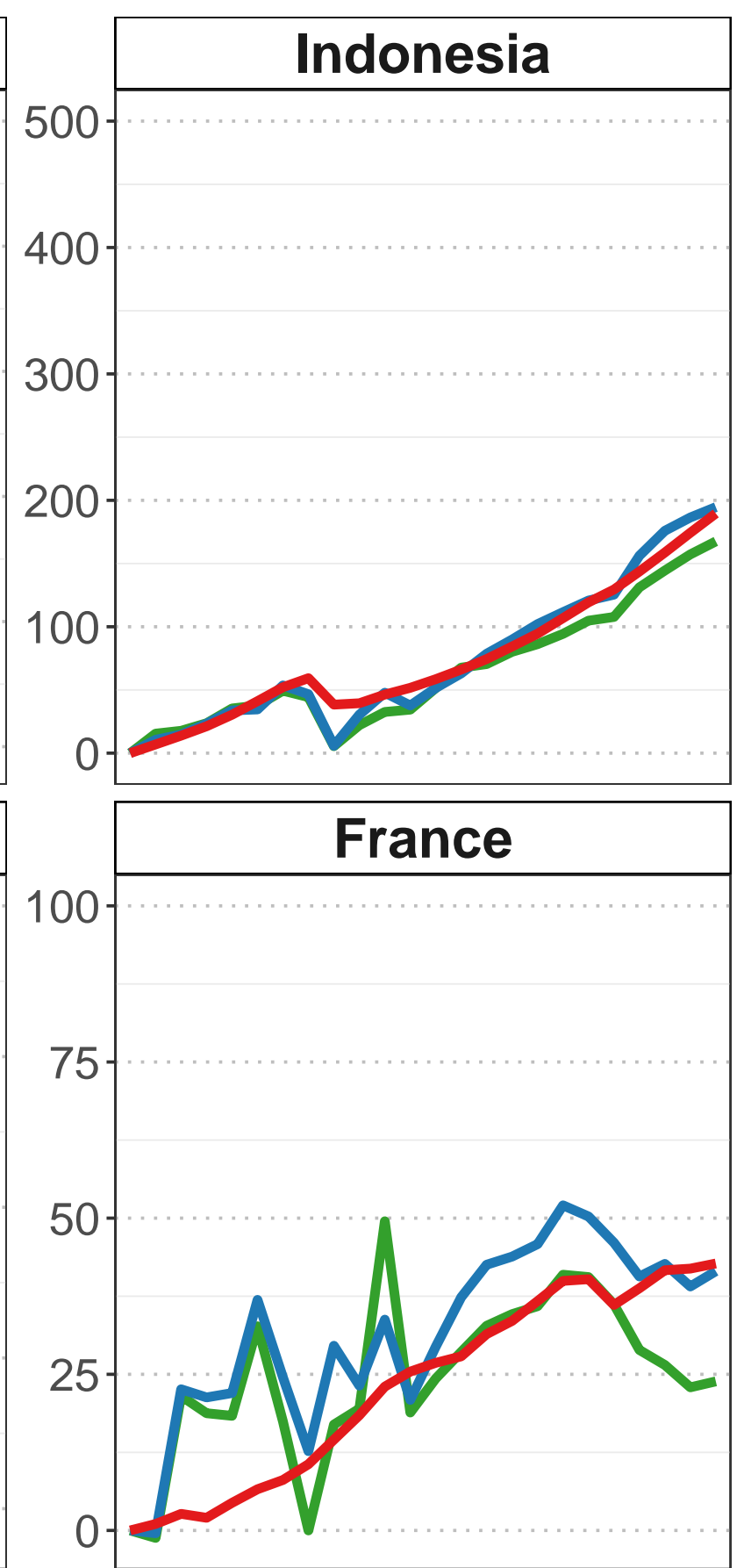

19901995200020052010

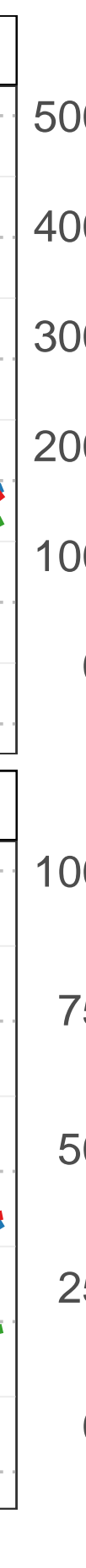

$$
\text { - Consumer - Value added - GDP }
$$

Russia

OECD 